\title{
Supply Voltage Effects on the Operation of Residential Air Conditioning Appliances: Theoretical Analysis
}

\author{
J.M. Maza Ortega ${ }^{1}$, M. Burgos Payán ${ }^{1}$, J.M. Romero Gordón ${ }^{2}$ and M. Pinilla Rodríguez ${ }^{2}$ \\ ${ }^{1}$ Department of Electrical Engineering, University of Seville \\ Camino de los Descubrimientos, s/n - 41092 Sevilla, Spain \\ phone: +34 954487283 - fax: +34 54487284 - e-mail: jmmaza@us.es, mburgos@us.es \\ ${ }^{2}$ Department of Power Quality - Endesa-Sevillana \\ Avda. de la Borbolla, 5 - 41004 Sevilla, Spain
}

\begin{abstract}
The deregulation of the electric energy market and the difficulties related to distribution network such as the congestion, the increasing growth of the installed power density in urban zones, the growth of the delivery-provided energy and the spectacular increase that the peak power experiences are new problems to be faced by the utility engineers. So, the knowledge of the load behaviour is becoming more and more important in the planning and operation of the electric energy distribution network.

In this paper, the influence of domestic air conditioning equipment, one of the most energy consuming domestic loads in Spain, in the electrical energy distribution network is addressed. The research is focused on analysis of the voltage supply effects on the operation of home air condition appliances, from a theoretical point of view. Some load models of the domestic air conditioning appliances as electrical load are considered.
\end{abstract}

\section{Key words}

Voltage regulation, Air conditioning equipment, Load modelling, Distribution network.

\section{Introduction}

The oil embargo crisis of 1973 forced the main electrical energy suppliers to start a series of research and activities to promote policies for the rational use of the energy and power saving. Among them, one of most significant and studied was the voltage reduction in the distribution networks (Conservation Voltage Regulation - NBC) [1].

These types of actions lie in controlling the network voltage by means of voltage regulators or changing the transformer taps. This way a power saving, changing the voltage out of his rated value, but within tolerable limits, could be obtained. So that, in the 80 's decade of the past century the scientific production dealing with the load modelling based on the voltage network was very relevant. Usually, these models consider the existing relation between the active power and reactive power and the voltage. Other models, oriented to analyze the power system transient stability, include the effect of the frequency variations [2].

Nowadays, the research community is showing a renewed interest for the load modelling for the electrical energy distribution network analysis. The basis of this renewed interest is now different (although the economic impact is the root again). The deregulation of the electric energy market and the difficulties related to the distribution network congestion, the increasing growth of the installed power density in urban zones, the growth of the delivery-provided energy and the spectacular increase that the peak power experiences are now the problems to be faced. So, the knowledge of the load behaviour is becoming more and more important in the planning and operation of the distribution power system.

As an example, during the last years in Spain the maximum power demand has been taken place during the summer, moving from the usual winter period. Two historic maxima consumption have taken place in 2005, one in summer and another one in winter, due to unusual cold weather.

Probably, one of the main causes of this the peak demand displacement is the massive installation and use of home air conditioning systems. In Spain, especially in Andalusia, the use of this type of electrical loads has been growing within the residential sector in the last years due to the reduction in cost, among others. This rather stepped change in the pattern of consumption within this residential sector obviously affects not only the operation of the system. The planning tasks are raised too. Nowadays, new load models to be included in the planning policies are needed.

In this report, the influence that the domestic equipment of air conditioning can have in the electrical energy distribution network is addressed. The research is focused on the theoretical analysis of the voltage supply effects on the operation of home air condition appliances. 
The paper content is as follows. After the introduction, a bibliographical survey about the incidences described in specialized literature related to the proliferation of residential air conditioning appliances in the distribution network is summarized. Then, the technologies more commonly used are described. After that, a theoretical description of the revised technologies behaviour versus voltage levels is addressed. Some load models of the domestic air conditioning appliances as electrical load are considered. Finally the main conclusions and some suggestions for future work are presented.

In a companion paper [3], some experimental results are reported.

\section{Air Conditioning Appliances as Electric Loads}

The massive installation and use of home air conditioning appliances in the distribution network has been previously reported in the specialized technical literature. As a summary, the main the following incidences have been reported:

- Voltage collapse [4,5]. The voltage reduction at the terminals of the residential air conditioning appliances reduces the electromagnetic motor torque driving the compressor. This reduction is very accused, because the electromagnetic motor torque is proportional to the voltage squared. In case of important voltage reductions, the maximum driving motor torque could be lesser than the compressor load one. This situation leads not only to a high current consumption scenario, but also to a high increase of the reactive power demand. This type of behaviour can explain some of the voltage collapses that took place in Japan $[4,5]$.

- Delay in the voltage recovery after short circuit faults [6]. The Southern Californian distributor Edison Company (SCE) reported some cases of service recovery incidents after faults in desert areas, in the periods of maximum air conditioning demand. A similar incident has been reported by the Municipal Sacrament Utility District. After a phasephase fault in the $230 \mathrm{kV}$ lines, cleared after 8.5 cycles, some tripping in the $12 \mathrm{kV}$ distribution lines were experienced. Some common aspects to these phenomena are the high density of electric load with a great air conditioning equipment penetration.

- Delay in residential sectors distribution networks recovery [7]. After a disturbance in the electrical power system, the power demanded by the load at the reclosing is slightly different from the previous situation to the disturbance. These differences not only affect the total power but also the behaviour of the equipment. This phenomenon is called cold load pick-up and follows the reclosing operation (programmed or not) in the distribution network. In the industrial sector, the power demanded after a reclosing uses to be lower to the previous one. But, in the residential sector the behaviour uses to be the opposite. Loads with thermostatic control (freezers, refrigerators, air conditioners, water heaters, and others) are the main responsible of this behaviour. When the voltage recovers after a service interruption, a great difference between the reference temperature and the actual temperature exists. This fact increases remarkably the electrical consumption in the distribution network. The power peak depends mainly not only on the time of the service interruption but also the outer temperature among other factors [8].

Taking into account all these phenomena is really possible to affirm that air condition appliances can mainly be modelled by means of the single phase induction motor (asynchronous) that drives the compressor. The fans of the inner units are of small power, reason why in first approach they can be eliminated of the analysis. A simplified analysis of air conditioning device takes to consider it as a single phase induction motor with run capacitor. This kind of loads behaves as impedances that depend mainly on the speed and, therefore, on the motor sliding s:

$$
\boldsymbol{Z}_{\text {INPUT }}(s)=R_{\text {INPUT }}(s)+\boldsymbol{j} X_{\text {INPUT }}(s)
$$

In normal operating conditions, when the speed comes near to the synchronism speed, the sliding comes near to zero and the real component of the impedance takes a value much greater than the reactance. The motor torque varies proportionally to the square of the voltage, so that when the feeding voltage is reduced, the speed descends (or the sliding grows) quickly what it is translated in a real component of the impedance very reduced (taking much load current). The induction motors with high inertia tend to maintain the speed if the voltage drop remain just a short time. Nevertheless, the motors with small inertia lose speed quickly. The motors that drive the compressors of the air conditioning appliances belong to this later class since the resistant torque of back pressure that offers the compressor quickly restrains the motor until the point that cannot reaccelerate to rated speed, although the voltage recovers the rated value.

\section{A. Voltage Drop}

The voltage drop by unit of length in mains of a low voltage distribution feeder, $\Delta U$, can be calculated using the following expression:

$$
\Delta U=\sqrt{3} I(R \cos \varphi+X \sin \varphi)=\frac{R P+X Q}{U}
$$

where $I$ is the current (modulus) that flows through the conductor, $R$ and $X$ are the resistance and reactance by unit of length of the conductor, and $P, Q$ and $\cos \varphi$ the power, reactive power and power factor of the fed loads. From this point of view, both the active and the reactive current or power components contribute to the voltage drop through the proportionally coefficients $R$ and $X$. The physical configuration of the distribution networks, with the conductors of the different phases located to little distance each other, causes that the predominant parameter of the low voltage distribution feeder is the resistance instead of the reactance (as used to be in high voltage overhead lines). 
Table I shows typical values of $R$ and $X$ parameters for low voltage and high voltage $(20 \mathrm{kV})$ cables with XLPE isolation used in the Spanish distribution networks. These data can be extracted from the voltage drop data at different power factors supplied by manufacturers catalogues. As can be seen, the value of the conductor resistance is always higher than the reactance. So, the voltage drop in low voltage distribution networks is mainly conditioned by the active current component.

Table I. Parameters $R$ and $X$ for low voltage cables with isolation XLPE and high voltage cables $(20 \mathrm{kV})$ with isolation XLPE.

\begin{tabular}{|c|c|c|}
\hline $\begin{array}{c}\text { Section } \\
{\left[\mathrm{mm}^{2}\right]}\end{array}$ & $\begin{array}{c}R \\
{[\Omega / \mathrm{km}]}\end{array}$ & $\begin{array}{c}X \\
{[\Omega / \mathrm{km}]}\end{array}$ \\
\hline \multicolumn{3}{|c|}{ Low Voltage } \\
\hline 25 & 1.54 & 0.08 \\
\hline 50 & 0.82 & 0.07 \\
\hline 95 & 0.41 & 0.09 \\
\hline 150 & 0.27 & 0.08 \\
\hline 240 & 0.16 & 0.07 \\
\hline \multicolumn{3}{|c|}{ High Voltage $(20 \mathrm{kV})$} \\
\hline 150 & 0.20 & 0.12 \\
\hline 240 & 0.12 & 0.10 \\
\hline
\end{tabular}

On the other hand, any increase of the current demanded by a load results in an increase of the voltage drop. From this point of view, two types of loads can be considered: those that demands less current in case of diminution of the voltage (incandescent illumination loads, resistive loads, and other) and other that increase to the consumption of current when diminishing the voltage (induction motors). In this sense, this last type of loads contributes of remarkable form to problems of transient stability in the power system, as they generate a problem of positive feedback that, in some cases, can lead to originate phenomena as previously presented.

\section{Air Conditioning Technology}

Nowadays, two main technologies for commercial home air conditioning appliances can be found:

- Conventional appliances. Compressor controlled by hysteresis temperature band

- Inverter based appliances. Compressor controlled by variable speed control

In both cases the objective is to reach a comfortable inside temperature, user selected, independent of the outside temperature. Nowadays in Spain, conventional appliances are the most broadly installed and used in the residential sector, due to their favourable cost. But the penetration of power electronic devices in the air conditioning sector is becoming bigger every day, due to the energy (and economic) saving derived of the variable speed control of the compressor.

\section{A. Conventional Air Condition Appliances}

The hysteresis control of a conventional air condition appliance can be explained with the help of Fig. 1. In this scheme, the user settles down a reference temperature that the equipment compares with the temperature of the space that is tried to conditioning. If the inner temperature is in a pre-established band around the reference temperature, the compressor it switched off the supply. On the contrary, when the inner temperature is out of the pre-established band, the compressor is connected to the mains.

These continuous starting and shutdown manoeuvres once reached a temperature near the reference one are very inefficient, from a power point of view, or by the disturbances that produce in the network (manoeuvres of starting and shutdown). In these periods of operation, the electrical motor is not driving the compressor at the speed that needs the process to obtain the wished temperature, since the motor speed is almost constant. This on-off behaviour originates considerable energy losses with their corresponding economical cost, and accelerates the equipment wear and stress. From an electromechanical point of view, and using the motor torque-speed characteristic, the system motor drive + compressor always works in the point of operation determined by the intersection of this characteristic with the compressor torque resistant characteristic, as shown in Fig. 2.

On the other hand, Fig. 3 shows how the air condition appliance adjusts the room temperature, once reached a temperature near the reference value. In this figure the time evolution of the total RMS load current demanded by the air condition appliance is shown. As can be seen a continuous and rather long sequence of starting and shutdown manoeuvres are need by this type of equipment to adapt the air room temperature to the wished reference value.

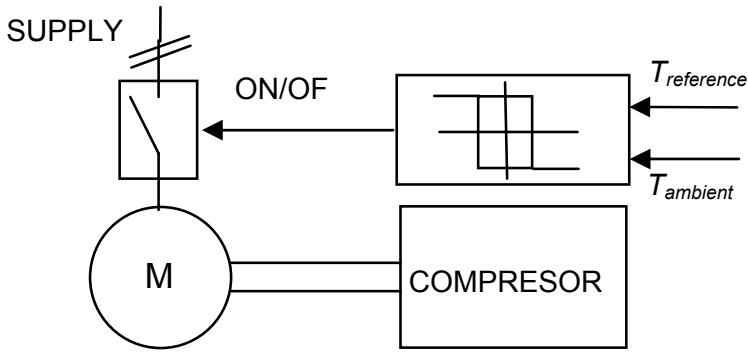

Fig. 1. Hysteresis control of an air condition compressor.

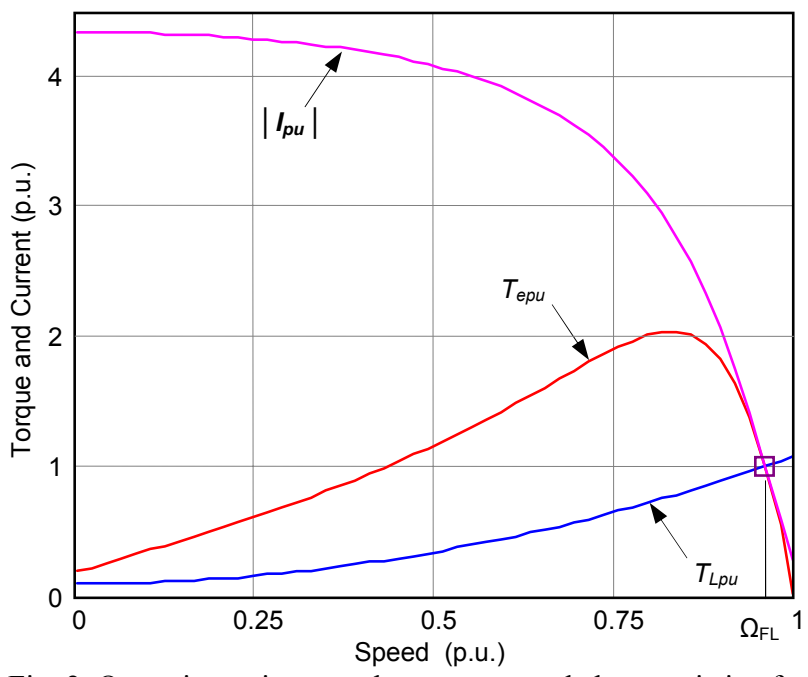

Fig. 2. Operating point over the torque-speed characteristic of a constant speed (conventional) drive air conditioning appliance. 


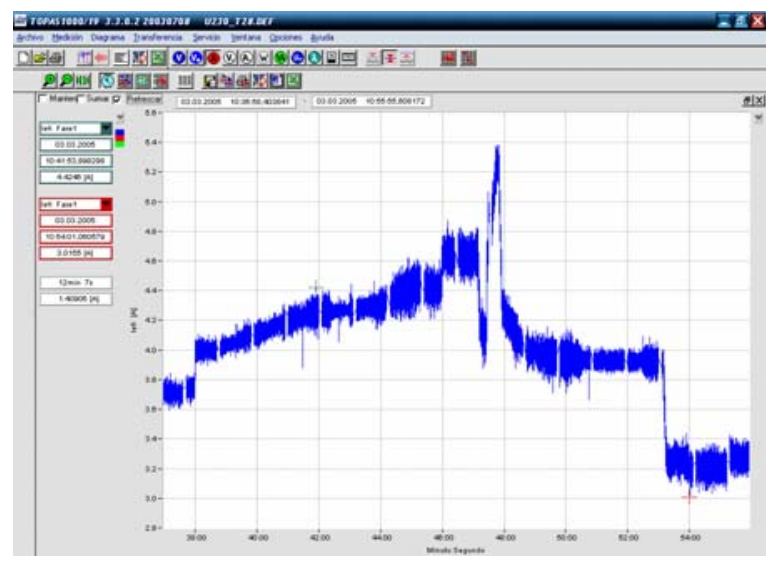

Fig. 3. Time evolution of the conventional air conditioning appliance total load current.

This behaviour due to the voltage variations can be explained with the aid of torque and current versus speed characteristics. Figure 4 shows a zoom of Fig. 2 in the neighbourhood of the synchronism speed. In this figure the compressor (resistant) torque curve (blue colour) and two motor torque curves (red colour), one for rated voltage $(U)$ and other for a reduced voltage value $(0.8 U)$, are shown.

The equilibrium (intersection) point of these curves (motor-load) determines the steady state point of the drive operation. As can be seen, a reduced voltage leads to a simultaneous reduction of both the speed and torque. As a consequence, there is a reduction of the demanded active power. Moreover, the current-speed characteristic shows that a reduction of the speed raises the current $(\Delta I>0)$. So, as a voltage reduction means a lower speed, this leads to a current increment $(\Delta I>0)$.

This is in well agreement with the simulation results shows in Fig. 5. As can be seen, a voltage reduction leads to a reduction of the speed, torque, power and power factor, but this produces a current increment. On the contrary, a voltage increment leads to an increment of the speed, torque and power and power factor, but this produces a current and power factor reduction.

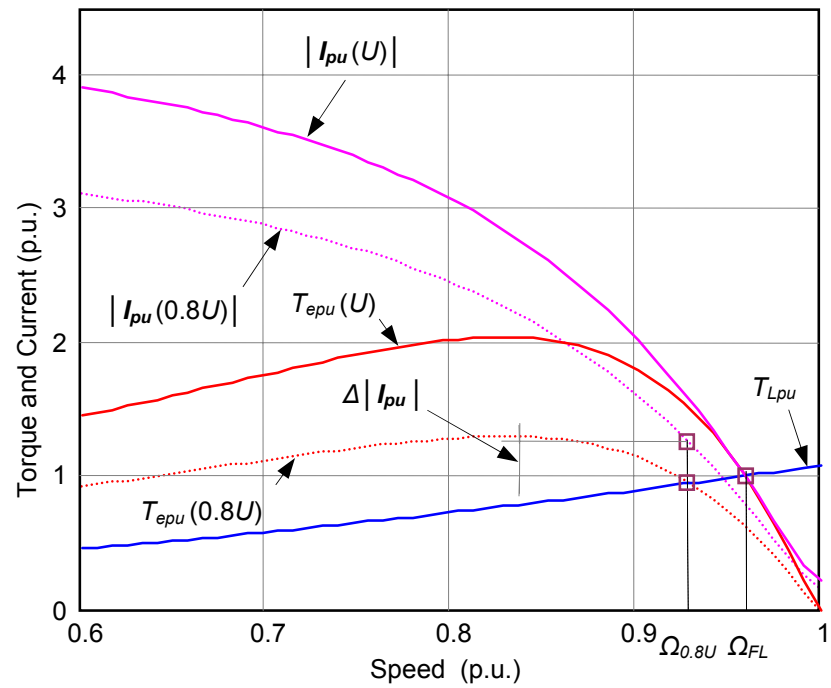

Fig. 4. Conventional appliance. Load current torque and speed variations due to voltage variations.

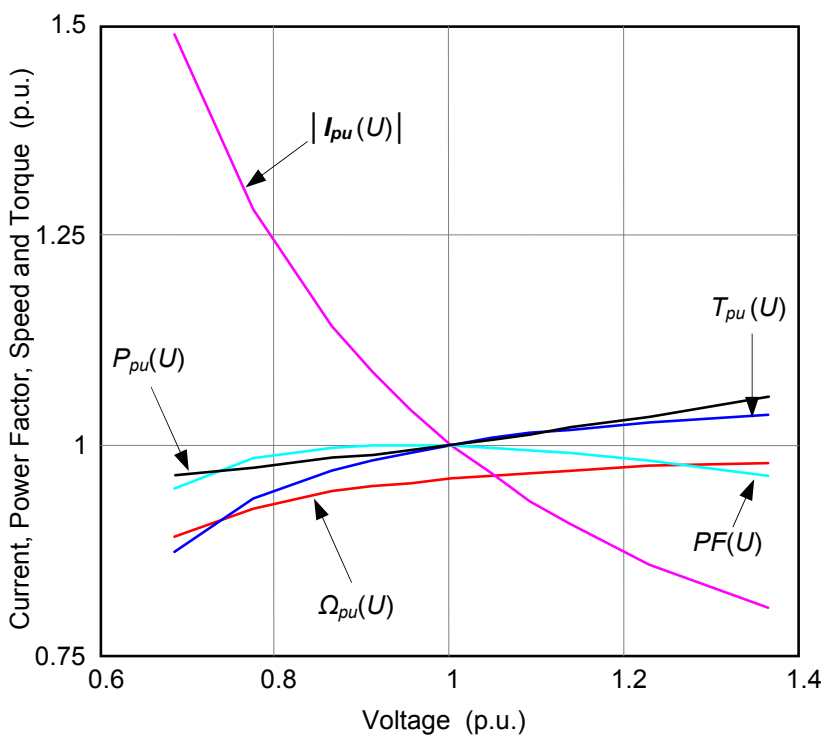

Fig. 5. Conventional appliance. Variation of load current, power, power factor, torque and speed due to voltage variations.

Figure 5 shows that the conventional air condition appliance, as an electrical load, could be successfully modelled as a combination of three simple constant loads: a constant admittance-impedance load $(Y-Z)$, constant current load $(I)$ and constant power load $(S-P$ $Q)$. As an example, the power, $P$, can be formulated as [6]:

$$
P=G_{P} U^{2}+I_{P} U+P_{P}
$$

where $G_{P}, I_{P}$, and $P_{P}$ are constants that can be determined from experimental data.

In the same way, it is possible to obtain expressions for the apparent power, current load and input admittance:

$$
\begin{gathered}
S=Y_{S} U^{2}+I_{S} U+S_{S} \\
I=\frac{S}{U}=Y_{S} U+I_{S}+\frac{S_{S}}{U} \\
Y=\frac{I}{U}=\frac{S}{U^{2}}=Y_{S}+\frac{I_{S}}{U}+\frac{S_{S}}{U^{2}}
\end{gathered}
$$

Similar polynomial adjustments could be done to model any other magnitude $(M)$ as power factor $(P F)$, speed $(\Omega)$ or torque $(T)$.

$$
M=K_{M 2} U^{2}+K_{M 1} U+K_{M 0}
$$

where $M$ is the magnitude to be modelled and $K_{M 2}, K_{M 1}$, and $K_{M 0}$ are the polynomial coefficients to be fitted from experimental data.

\section{B. Inverter Air Condition Appliances}

On the other hand, in the case of motor speed control, the compressor is driven by an inverter, as shown in Fig. 6. This inverter, through the variation of the voltage and the frequency used to supply the motor is able to modify the speed of the drive in a smooth and continuous form. This 
way, the compressor can be always driven at the speed that requires the thermodynamic process.

From an energy point of view, the speed control of the drive is very well suited because the speed of the compressor can bee adjusted to the exact values needed by the process.

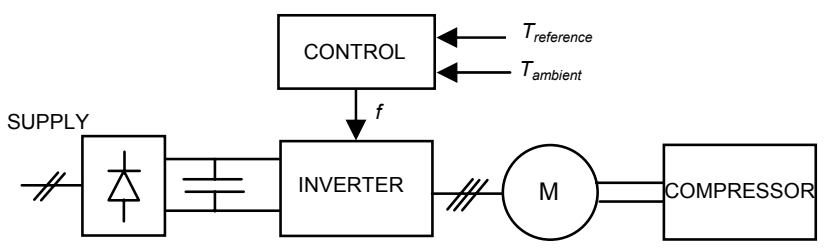

Fig. 6. Inverter control of an air conditioning appliance compressor

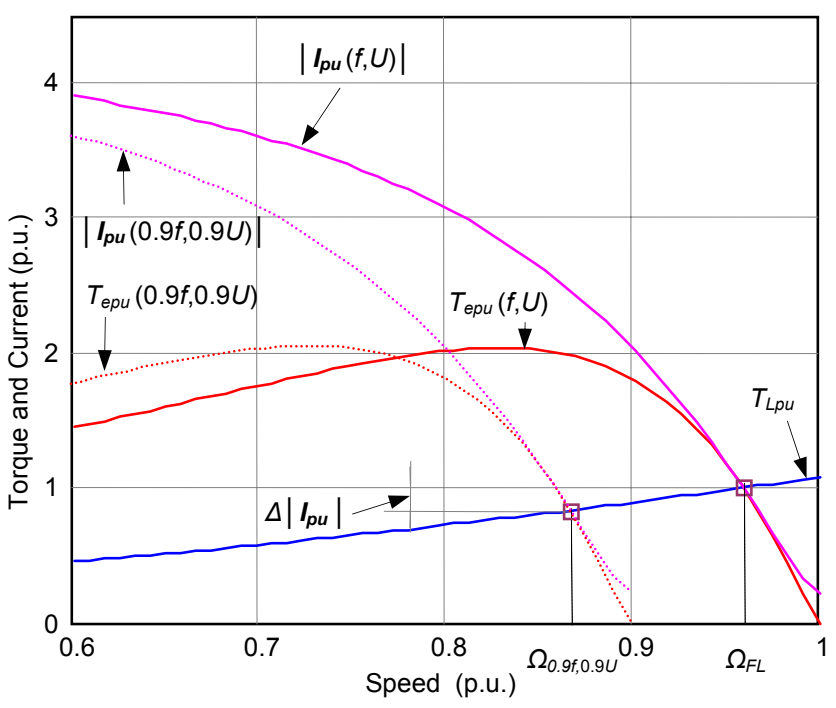

Figura 7. Operating points over the torque-speed characteristic of a variable speed drive (inverter) air condition appliance.

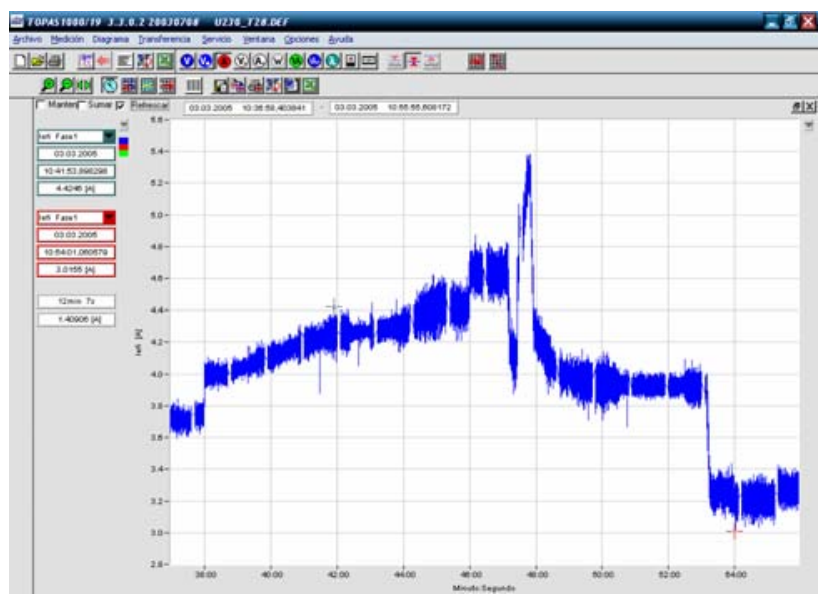

Fig. 8. Time evolution of an inverter air conditioning appliance total load current.

As a consequence, when the room temperature is near the reference values, the frequency varies to fit the operation point, taking into account the available voltage supply. This leads to a reduction of the drive current load. In addition, the network perturbations associated to the continuous starting and shutdown manoeuvres are reduced. This behaviour can be seen in Fig. 7 that shows both the mechanical and electrical motor torque-speed characteristics with the different operation points that can bee reached through frequency and voltage variation or adjustment.

This way, when the room temperature is near the reference value, the load current demanded is almost constant and lower than the rated value. So, an energy saving is reached. Fig. 8 shows the time evolution of the inverter air condition appliance load current.

The behaviour of the conditioned air equipment with inverter can be explained from a theoretical point of view with the aid of figures 9 and 10. In these figures, a zoom of the normal operation zone is shown again, with a small sleep and a speed near the synchronism value.

Figure 9 shows the compressor resistant torque characteristic and the electromechanical torque developed by the motor for three different combinations of voltage and frequency: rated voltage and frequency, reduced voltage and rated frequency and, finally, reduced voltage and a frequency higher than the rated value. As can be seen in Fig. 9, with rated voltage and frequency, the motor and the compressor load system worked in a steady state point with a speed higher than 0.95 p.u. and rated torque. If the frequency is kept constant at the rated value but the motor feeding voltage is reduced from the rated value, a new a steady state point with a speed lower than 0.95 p.u. is reached (this is similar to shown previously in the conventional drive case). Nevertheless, since this device integrates inverter technology and a control system, the frequency is increased to take to the compressor again at the speed required by the thermodynamic process, this is, the first point of operation (rated voltage and frequency point or rated speed and torque point).

So, as a result of the performance of the inverter and the control system, this kind of electrical load behaves has an almost constant power load, due to the fact that the theoretical point torque-speed required by the thermodynamic process is tracked by the control device.

The analysis of the drive (motor-compressor system) behaviour based on the torque-speed mechanical characteristics supports the explanation of the current behaviour as a result of voltage variations.

Figure 10 shows the operating points over the currentspeed characteristic of a variable speed drive (inverter) air condition appliance for the three different combinations of voltage and frequency (rated voltage and frequency, reduced voltage and rated frequency and, finally, reduced voltage and a frequency higher than the rated value). As can be seen, with rated voltage and frequency, the motor-compressor system worked at a steady state point with a speed higher than 0.95 p.u. and rated current. If the frequency is kept constant at the rated value but the motor feeding voltage is reduced from the 
rated value, a new a steady state point with a speed lower than 0.95 p.u. and a current higher than 1 p.u. is reached. Now the control system increases the frequency to take the compressor again at the speed required by the thermodynamic process (higher than 0.95 p.u.), but now the current is higher than 1 p.u.

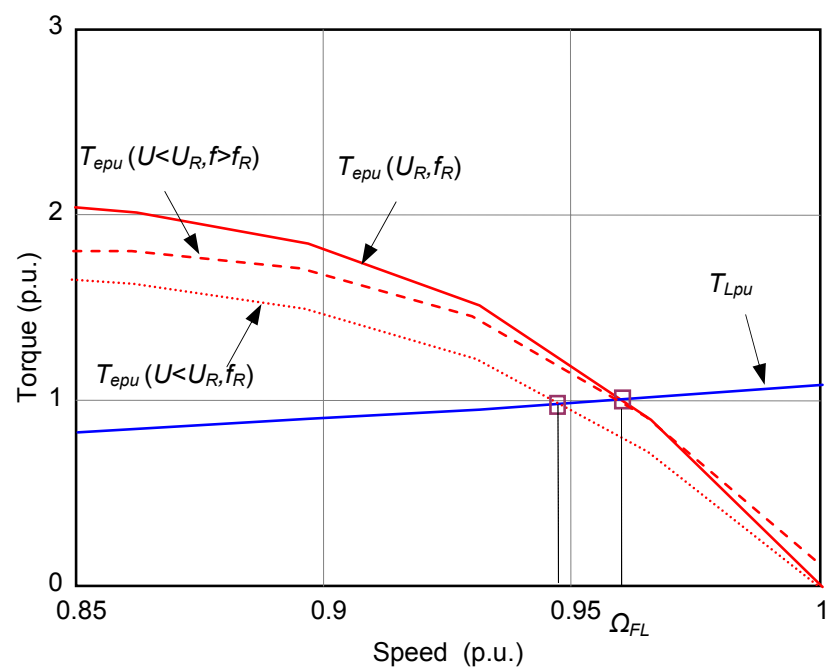

Figura 9. Operating points over the torque-speed characteristic of a variable speed drive (inverter) air condition appliance for three different combinations of voltage and frequency.

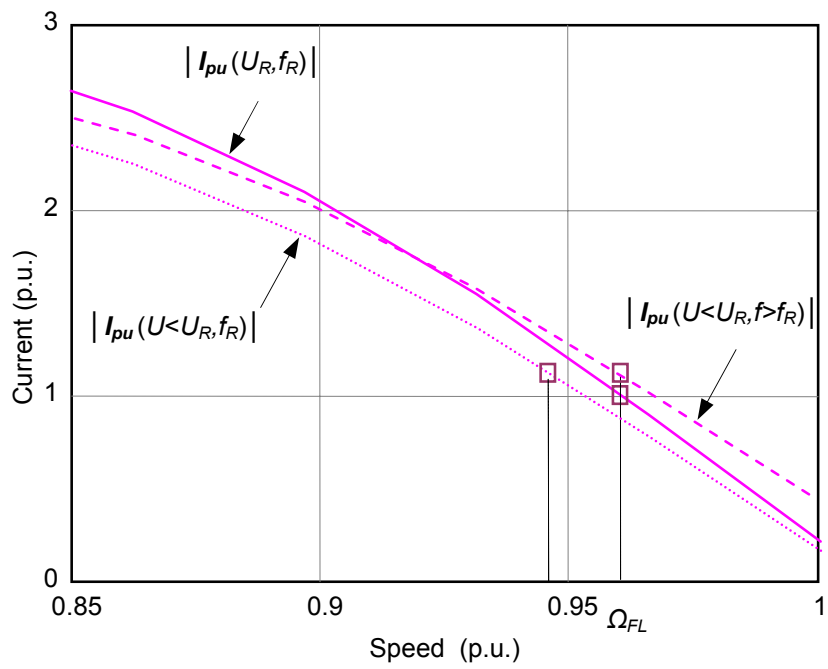

Figura 10. Operating points over the current-speed characteristic of a variable speed drive (inverter) air condition appliance for three different combinations of voltage and frequency.

\section{Conclusion}

The main conclusions derived from this theoretical approach focused on the effects of the voltage variation on the operation of home air conditioner appliances are summarized as follows.

- Conventional appliance

0 A moderate voltage reduction increases the current load and reduces the power demand $(P$ and $Q)$. o Higher voltage reductions increase the reactive power demand as the capacitor drastically reduces the reactive power compensation. This considerable increase in the reactive power demand can lead to situations as the described in the literature.

o The air conditioner load can be successfully modelled as a combination of three constant loads $(Z, I$ and $P)$ as shown in (1)-(3).

- Inverter appliance

o As in the case of the conventional equipment, a reduction of the feeding voltage leads to an increase of the load current.

o This type of loads can be successfully modelled (in a first approach) as constant power loads $(P)$. This is due to the performance of the control system that modifies the feeding frequency to fit the speed.

o From a power point of view this type of equipment is a priori more efficient than the conventional one, because the compressor always works in the optimal point required by the thermodynamic process. Nevertheless, this type of devices behaves as nonlinear load, so they generate harmonics that could cause problems in the distribution networks.

In both cases, the effect on the distribution network voltage drop as a result of the greater demands of current due to voltage reduction is more active current or power dependent that reactive current or power dependent.

\section{Acknowledgement}

The authors wish to acknowledge Endesa-Sevillana for the financial support of this work.

\section{References}

[1] EPRI EL-2036, Volume 1, "Effects of Reduced Voltage on the Operation and Efficiency of Electric Load", September 1981.

[2] IEEE Task Force on Load Representation for Dynamic Performance, "Bibliography on Load Models for Power Flow and Dynamic Performance Simulation", IEEE Trans. On Power Systems, Vol. 10, No. 1, Feb. 1995, pp. 523-538.

[3] J.M. Maza, M. Burgos, J.M. Romero and M. Pinilla, "Supply Voltage Effects on the Operation of Residential Air Conditioning Appliances: Experimental Analysis", International Conference on Renewable Energy and Power Quality - ICREPQ-07, Sevilla, 2007.

[4] A. Kurita, T. Sakura, "The Power System Failure on July 23, 1987 in Tokyo", Proceedings of the $27^{\text {th }}$ Conference on Decision and Control, Austin, Texas, December 1988, pp. 2093-2097. 
[5] K. Tomiyama, J.P. Daniel, S. Ihara, "Modelling Air Conditioned Load for Power System Studies", IEEE Trans. on Power Systems, Vol. 13, No. 2, May 1998, pp. 414-421.

[6] B.R. Williams, W.R. Schmus, D.C. Dawson, "Transmission Voltage Recovery Delayed by Stalled Air Conditioner Compressors", IEEE Trans. on Power Systems, Vol. 7, No. 3, August 1992.
[7] E. Agneholm, J. Daalder, "Cold Load Pick-Up of Residential Load", IEE Proc. on Generation, Transmission and Distribution, Vol. 147, No. 1, January 2000.

[8] L.M. Hajagos, B. Danai, "Laboratory Measurements and Models of Modern Loads and Their Effect on Voltage Stability Studies", IEEE Trans. on Power Systems, Vol. 13, No. 2, May 1998, pp. 584-592. 